\title{
Assessment of the Medical Students Preparedness and Willingness for Integration into a War-torn Healthcare System: The example of COVID-19 Pandemic Scenario
}

\section{Tamim Alsuliman}

Saint Antoine hospital, AP-HP, Sorbonne University

\section{Lugien Alasadi}

Damascus University Faculty of Medicine

Rahim Abo Kasem ( Rahimabu99@gmail.com)

Damascus University Faculty of Medicine https://orcid.org/0000-0002-9635-7471

\section{Majd Hawat}

Damascus University Faculty of Medicine

\section{Mohammad Almansour}

Damascus University Faculty of Medicine

\section{Ruba Al Khalaf}

University of Milan , Department of Biosciences

\section{Marwan Alhalabi}

Damascus University Faculty of Medicine

\section{Research}

Keywords: COVID-19, Undergraduates, Preparedness, Health Systems, Integration

Posted Date: December 18th, 2020

DOI: https://doi.org/10.21203/rs.3.rs-130223/v1

License: (a) (i) This work is licensed under a Creative Commons Attribution 4.0 International License. Read Full License

Version of Record: A version of this preprint was published at Medicine, Conflict and Survival on December 16th, 2021. See the published version at https://doi.org/10.1080/13623699.2021.2015828. 


\section{Abstract}

Background: The question about the role of the senior medical students in the fight against COVID-19 pandemic was raised after the serious shortage in healthcare workers faced by many healthcare systems. This research aimed to explore the ability of the final-year medical students to assist during COVID-19 in a war-torn health system.

Methods: Final-year medical students in Syrian Universities were approached between $9^{\text {th }}-17^{\text {th }}$ April 2020 through an online questionnaire that assessed the students' COVID-19-related medical knowledge (5-point score), clinical judgment (5-point score), preparedness and willingness to integrate in the healthcare facilities. An overall score of 10 points was built and multivariate analysis was conducted.

Results: A total of 1764 responses were received. Valid responses were (1673) with 1199 (71.66\%) responses from the final-year students. Of the latter, $728(60.71 \%)$ scored 4 points or higher in the medical knowledge score (mean 3.69 points [SD 0.96]), while 298 (24.85\%) scored 4 or higher in the clinical judgment score. Final-year students scored significantly higher than the fourth-year students in the clinical judgment score (mean 2.69 points [SD 1.12] vs 2.47 [1.15]; adjusted $P=0.012$ ). Nearly $72.4 \%$ of the final-year participants had an overall score of 7 points or more out of 10 (mean 6.39 points [SD 1.57]). Having fears of infection ( $\log \mathrm{OR} 0.24,95 \% \mathrm{Cl} 0.05-0.44 ; \mathrm{P}=0.01$ ) correlated with a higher overall score, contritely to beginner, intermediate English level, and male gender (log OR -0.68 [95\% Cl -1.01- -0.35]; $P<0.001,-0.3[-0.5--0.1] ; P=0.003,-0.25[-0.43--0.08] ; P=0.004$, respectively). Finally, $682(56.88 \%)$ of the final-year students expressed willingness to volunteer with healthcare teams.

Conclusion: Integrating final-year medical students may be an alternative in case of pandemics especially for fragile systems or those hit by a long-lasting war, while taking into consideration fulfilling personal protective measures, intensive training, and/or adequate supervision.

\section{Background}

Severe acute respiratory syndrome coronavirus 2 (SARS-CoV-2) was first identified in Wuhan, China, with rapid expansion all over the world since December 2019.[1] On March 11th, the World Health Organization (WHO) announced COVID-19 as a pandemic, thus, this has made it an urgent need to prepare health systems around the world to meet a new challenge.[2]

Several previous epidemics and health crisis prompted the health systems to reconsider their health policies. Due to the Ebola outbreak in 2014-2016 in West Africa, fragile health systems were quickly put under the pressure of many challenges like detecting infected cases and adopting appropriate health plans for disease management and prevention.[3, 4] Likewise, in other epidemics, Severe Acute Respiratory Syndrome (SARS) and Middle East Respiratory Syndrome (MERS), unprepared health systems have demonstrated an apparent defect in providing services and a shortage of healthcare providers, this was the situation even in more developed countries, e.g., Canada during SARS and Korea during MERS, where healthcare facilities may have even had a role in disease dissemination. $[4,5]$ 
Many countries have dedicated more resources and efforts toward health system enhancement based on lessons obtained from these epidemics and other health crises, but no actionable approaches for more resilient health systems have been achieved globally yet.[4] With the increasing numbers of COVID-19 cases and deaths, many health systems are still experiencing a chronic shortage of health workers.[2, 6] This raised the question about the role of junior graduates and senior medical undergraduates in the battle against this pandemic. Some schools prevented students from interacting with patients, while others recruited them to work with healthcare workers (HCWs).[7] During the COVID-19 pandemic, The Association of American Medical Colleges (AAMC) recommended that it may be the best for the students safety to limit student direct care of COVID-19 cases,[8] and highlighted the unnecessary risks for the patients and HCWs caused by non-qualified medical students. It also emphasized the additional burden on physicians/educators.[7] On the other hand, some UK Medical schools have been granted the power to graduate their students early,[9] and in Italy, a plan was put to call on final-year and graduated medical students to meet the demand and support the workforce.[6]

In Syria, the long-lasting war had an intensive influence on every aspect of life, amongst the healthcare system and education. For that reason, at least partially, the WHO has classified Syria among the COVID19 high-risk countries in the Eastern Mediterranean Region.[10]

Medical education in Syrian Universities consists of six academic years, the first three years include subjects more related to basic sciences, while students in the fourth and fifth years have more clinical education and start training in the University hospitals. These clinical training rotations are re-performed during the sixth year, and at the end of this year students are required to pass a national certification exam in order to be allocated to different specialization programs.[11] This research was designed to determine the ability of the Syrian final-year medical students to provide assistance in combating the COVID-19 pandemic through integration into a Fragile war-torn health system.

\section{Methods}

\section{Study design:}

A cross-sectional questionnaire was conducted online through social networks from 9th till 17th April 2020. The targeted population was the sixth-year medical students in Syrian Universities. The fourth and fifth year students were allowed to submit the questionnaire in order to use their responses as a comparison group during data analysis. The minimum required sample size was (204) based on statisticians Borg and Gall recommendations[12] and on the available statistics from the Higher Ministry of Education in Syria.

\section{Study tools:}

The questionnaire was built using Google forms ${ }^{\circledR}$ and it was designed to assess medical knowledge, clinical judgment, preparedness and willingness to interfere in the healthcare facilities. The questionnaire consisted mainly of 4 sections (detailed in the Additional file 1) with a total of 6 pages containing 29 
items. Questions and answers were presented in both Arabic and English. All the questions and clinical cases were based on the global COVID-19 guidelines and recommendations,[13] and underwent two independent scientific revisions before launching it online.

\section{Data analysis:}

Data were anonymously imported into an EXCEL $®$ file and saved on a secured laptop. After processing, the data were analyzed using $\mathrm{R}[14]$ software version 3.5.3 and the $\mathrm{R}$ studio environment and data visualization was obtained by seaborn,[15] The Shapiro-Wilk normality test, Unpaired t-test, Pearson's Chisquared test, one way analysis of variance (one way ANOVA) test, and Tukey's HSD test were used during the statistical analysis. A P-value of $\leq 0.05$ was considered significant. Furthermore, both medical knowledge and clinical judgment items were assessed according to five-point scores with an added overall score of 10 points. Linear regression fitting model was used to determine the factors that significantly affected the overall score for the final-year medical students. The model included: university of the participant, gender, English level, need for supervision and having fears of getting infected.

\section{Ethical considerations:}

The study was approved by the Scientific Ethical Committee of the Faculty of Medicine, Damascus University, and was conducted in line with the Declaration of Helsinki. Written informed consent was obtained from each respondent on the first electronic page of the questionnaire. Participants' privacy was guaranteed throughout the study. All participants had the right to withdraw at any stage of the study. Moreover, all incomplete responses were considered as withdrawal and were excluded from the analysis. All participants were 18-year-old or older.

\section{Results}

\section{Participants' characteristics:}

A total of 1764 responses were received; 1710 (96.94\%) of respondents approved to participate, while 55 (3.12\%) refused. The latter responses were excluded along with invalid, empty and incomplete ones. A total of $1673(94.84 \%)$ responses were included from 11 different universities; 1199 (71. 66\%) of participants were sixth-year medical students, while 221 (13.2\%) were fifth-year students, and 253 $(15.12 \%)$ were fourth-year medical students. The characteristics of the participants including gender, universities and year of study are summarized in (Table 1). 
Table 1

Characteristics of participant of all (fourth, fifth, and sixth year) and final (sixth)-year medical students.

\begin{tabular}{|c|c|c|c|}
\hline \multirow[t]{3}{*}{ Characteristics } & & \multicolumn{2}{|l|}{ Number (\%) } \\
\hline & & All Participants & Sixth-Year Students \\
\hline & & $(n=1673)$ & $(n=1199)$ \\
\hline \multirow[t]{3}{*}{ Academic year } & Fourth year & $253(15.12)$ & - \\
\hline & Fifth year & $221(13.2)$ & - \\
\hline & Sixth year & 1199 (71.58) & - \\
\hline \multirow[t]{2}{*}{ Gender } & Females & $818(48.89)$ & $589(49.12)$ \\
\hline & Males & $855(51.10)$ & $610(50.88)$ \\
\hline \multirow[t]{11}{*}{ University } & Damascus university & $896(53.55)$ & 719 (59.97) \\
\hline & Aleppo university & $365(21.81)$ & $170(14.18)$ \\
\hline & Tishreen university & $160(9.56)$ & 139 (11.59) \\
\hline & Hama university & $24(1.43)$ & $17(1.42)$ \\
\hline & Al-Baath university & $104(6.21)$ & $82(6.84)$ \\
\hline & Al-Furat university & $4(0.24)$ & $2(0.17)$ \\
\hline & Tartus university & $29(1.73)$ & $18(1.50)$ \\
\hline & Al-Kalamon university & $27(1.61)$ & $19(1.58)$ \\
\hline & Syrian private university & $38(2.27)$ & $13(1.08)$ \\
\hline & AL-Hawash university & $3(0.17)$ & $2(0.17)$ \\
\hline & Al-Andalus university & $23(1.37)$ & $18(1.50)$ \\
\hline \multirow[t]{3}{*}{ English level } & Beginner & $156(9.32)$ & $118(9.84)$ \\
\hline & Intermediate & $1081(64.61)$ & $761(63.46)$ \\
\hline & Advanced & $436(26.06)$ & $320(26.68)$ \\
\hline
\end{tabular}

\section{General medical knowledge assessment:}

The answers of this section were normally distributed (P-value $=0.54)$. About $40 \%$ of the sixth-year medical students had a score of 4 points, while those who scored 4 or 5 points were $728(60.71 \%)$.

Comparing these results with the answers of the fourth- and fifth-year students, no significant correlation between general medical knowledge score and the current academic year was found (mean 3.69 points 
[SD 0.96], 3.78 points [0.9], and 3.7 points [0.98] for the sixth-, fifth- and fourth-year, respectively; P-value = 0.43). Results of this section are summarized in (Fig. 1, Additional file 1 Figure S1 and S2).

However, a significant correlation between general medical knowledge score among sixth-year students and the university of the participant (P-value $<0.001$ ) was found (Table 2, Additional file 1 Table S1). In addition, sixth-year students with advanced English level scored higher in this section than those with beginner English level (adjusted P-value $=0.01$ ).

Table 2

Results of the General knowledge Score, Clinical judgment Score, and Overall Score among the participants.

\begin{tabular}{|c|c|c|c|c|c|c|c|c|}
\hline \multirow[t]{2}{*}{ Population } & \multirow{2}{*}{\multicolumn{2}{|c|}{ Variables }} & \multicolumn{2}{|c|}{$\begin{array}{l}\text { General knowledge } \\
\text { Score ( } 5 \text { points) }\end{array}$} & \multicolumn{2}{|c|}{$\begin{array}{l}\text { Clinical judgment } \\
\text { Score (5 points) }\end{array}$} & \multicolumn{2}{|c|}{$\begin{array}{l}\text { Overall Score } \\
\text { (10 points) }\end{array}$} \\
\hline & & & Mean & P Value & Mean & P Value & Mean & $\begin{array}{l}P \\
\text { Value }\end{array}$ \\
\hline \multirow[t]{3}{*}{ All years } & \multirow{3}{*}{$\begin{array}{l}\text { Year of } \\
\text { study }\end{array}$} & Fourth-year & 3.70 & \multirow[t]{3}{*}{0.43} & 2.47 & \multirow[t]{3}{*}{0.01} & 6.17 & \\
\hline & & Fifth-year & 3.78 & & 2.71 & & 6.49 & \\
\hline & & Sixth-year & 3.69 & & 2.69 & & 6.39 & \\
\hline \multirow[t]{12}{*}{ 6th year } & \multirow{3}{*}{$\begin{array}{l}\text { English } \\
\text { level }\end{array}$} & Beginner & 3.52 & \multirow[t]{3}{*}{0.009} & 2.48 & \multirow[t]{3}{*}{0.02} & 6.00 & \multirow{3}{*}{$\begin{array}{l}<.001 \\
0.001\end{array}$} \\
\hline & & Intermediate & 3.66 & & 2.68 & & 6.34 & \\
\hline & & Advanced & 3.81 & & 2.81 & & 6.62 & \\
\hline & \multicolumn{2}{|c|}{ University } & & $<0.001$ & & 0.01 & & $\begin{array}{l}< \\
0.001\end{array}$ \\
\hline & \multicolumn{2}{|c|}{$\begin{array}{l}\text { Last department of } \\
\text { clinical training }\end{array}$} & & 0.46 & & 0.58 & & 0.60 \\
\hline & \multicolumn{2}{|c|}{ Willingness to volunteer } & & 0.37 & & 0.15 & & 0.08 \\
\hline & \multirow[t]{2}{*}{ Gender } & Female & 3.66 & \multirow[t]{2}{*}{0.37} & 2.84 & \multirow[t]{2}{*}{$<0.001$} & 6.51 & \multirow[t]{2}{*}{0.006} \\
\hline & & Male & 3.71 & & 2.55 & & 6.26 & \\
\hline & \multicolumn{2}{|c|}{ The need of supervision } & & 0.24 & & 0.02 & & 0.03 \\
\hline & \multicolumn{2}{|c|}{ Fears of being infected } & & 0.18 & & 0.01 & & 0.008 \\
\hline & \multicolumn{2}{|c|}{ Previous experience } & & 0.96 & & 0.27 & & 0.39 \\
\hline & \multicolumn{2}{|c|}{$\begin{array}{l}\text { The source of } \\
\text { information }\end{array}$} & & 0.10 & & 0.34 & & 0.09 \\
\hline
\end{tabular}




\section{Clinical judgments assessment:}

The answers of this section were normally distributed $(P$-value $=0.58)$. In this section, the most frequent achieved score was 3 points (33.7\%), while only 298 (24.8\%) of the sixth-year participants scored 4 points or higher, as shown in (Fig. 2, Additional file 1 Figure S3 and S4).

Regarding clinical judgment score, the sixth-year students obtained a significantly higher score than the fourth-year students (mean 2.69 points [1.12] vs 2.47 points [1.15]; adjusted $P=0.01$ ). However, the difference was not significant in comparison to the fifth-year students (mean 2.71 points [1.15]; adjusted P-value $=0.98$ ). Further analysis of the final-year students' responses revealed a significant correlation between clinical judgment score and the participant's university $(P$-value $=0.01)$. As with the general knowledge, sixth year students with advanced English level obtained a higher clinical judgment score than those with a beginner English level (adjusted P-value $=0.01)$. Females scored significantly higher (Pvalue $<0.001$ ) in clinical judgment than males (Additional file 1 Table S2).

\section{Overall score:}

An overall score of 10 points was generated based on the addition of the aforementioned two scores (general knowledge and clinical judgment). Nearly $72.4 \%$ of the sixth-year participants had an overall score of 7 points or more out of 10 (Fig. 3). Univariate analysis results are shown in (Table 2, Additional file 1 Table S3). Linear regression fitting model revealed that having fears of infection (log OR 0.24, 95\% $\mathrm{Cl} 0.05-0.44 ; \mathrm{P}=0.01)$ correlated with a higher overall score. While beginner $(\log \mathrm{OR}-0.68[95 \% \mathrm{Cl}-1.01-$ $-0.35] ; P<0.001)$ and intermediate ( $\log O R-0.3$ [-0.5 - -0.1]; $P=0.003)$ English level, and male gender (log OR -0.25 [-0.43 - -0.08]; $P=0.004$ ) correlated with a lower overall score). However, certain universities were correlated with a lower overall score of the participants (Additional file 1 Figure S5 and Table S3). Multivariate analysis using one-way ANOVA also confirmed the correlation with the aforementioned three factors.

\section{Willingness and preparedness to intervene in healthcare facilities:}

Of the sixth-year participants, 682 (56.8\%) expressed their willingness to volunteer with health care workers. No significant correlation was found between willingness to volunteer and general medical knowledge or clinical judgment scores (P-value $=0.37$, and 0.15 , respectively). Moreover, no significant correlation between the willingness to volunteer and the current academic year of the

applicant (P-value $=0.34)$.

There was a significant correlation between the fear of getting infected and the current academic year ( $P$ value $<0.001) ; 678$ (56.54\%) of sixth-year students were scared of getting infected in comparison with $105(41.5 \%)$ and $115(52 \%)$ of the fourth- and fifth-year students, respectively. The students who 
expressed ability to manage the airways and to have a basic understanding of mechanical ventilation reported more willingness to volunteer ( $P$-value $<0.001)$.

As for the need of supervision, $96.33 \%$ of the sixth-year students expressed the need for a supervisor, while $90.99 \%$ of them chose the correct type of supervisors (mainly a doctor). Those who needed supervision expressed more ability to manage airways and perform mechanical ventilation but had more fears of being infected (P-value $<0.001$ in both scenarios).

Only 707 (58.9\%) final-year students, of those who answered subjectively that they know how to follow the prevention rules (1036 [86.4\%]), answered prevention-related questions correctly. There was no significant correlation between knowledge of the preventive measures and having fears of being infected $(P$-value $=0.95)$. Finally, willingness to volunteer was higher $(P$-value $<0.001)$ among those who did not have fears of being infected (Additional file 1 Table S4 and S5).

\section{Discussion}

COVID-19 pandemic has caused a lot of controversy about the role of medical undergraduates, especially final-year students. Attitudes and decisions varied among countries. Some institutions prompted medical students to participate in supporting medical staff and HCWs during the epidemics, while some others considered graduating them earlier. For example, during the Spanish flu outbreak in 1918, medical students at the University of Pennsylvania were assigned the roles of physicians and nurses in order to care for patients, often without supervision.[16]

Integrating medical students in the health care process during crises and defining their role has been the subject of numerous previous studies. Several studies were carried out in Saudi Arabia during the MERSCoV outbreak aiming at assessing some aspects related to medical knowledge, attitudes and readiness to engage the medical colleges students in the healthcare system.[17] Other studies focused on the assessment of awareness, perception, and medical knowledge of seasonal influenza among medical students in Pakistan,[18] Vietnam and the United States.[19]

In Syrian scenario, thousands of doctors fleet their ways out of the country. It was announced, allegedly as a part of the response plan to COVID-19, that final year medical students should be put on-call in order to be integrated into medical teams as soon as possible should needed.[20] This study aimed to evaluate the preparedness and willingness of these students to be part of the first-line medical teams in the battle against COVID-19.

Results revealed that the overall level of general knowledge related to risk groups, prevention measures, diagnosis and treatment was considerable. It showed that $(60.71 \%)$ of sixth-year participants scored 4 points out of 5 or higher in the general medical knowledge section, whereas, only $10.34 \%$ of the participants scored less than 3 points. Several studies tried to assess the level of medical knowledge of COVID-19 in different populations. In a study held in Iran it was found that Iranian medical students have a high level of COVID-19-related medical knowledge.[21] Another study aimed at investigating the 
knowledge about COVID-19 among HCWs globally, the results revealed that HCWs have insufficient knowledge about COVID-19, but they showed a positive perception of COVID19.[1]

Importantly, the present study did not conclude any significant association between the year of study and the level of general medical knowledge. This may be due to the ease of access to reliable information resources related to COVID-19 and to the fact that the study targeted only the second educational cycle of medical school (fourth, fifth, and sixth year) in which the basic medical and epidemiological knowledge in every year is quite close to those in the others.[22] Furthermore, the results indicated that the general COVID-19 related medical knowledge did not correlate with the type of information source, which may be explained by the high availability of information on most platforms.[23]

Results of the clinical judgment assessment, on the other hand, revealed that most (58.5\%) of the finalyear medical students had a score of 3 or more out of 5 . These results could be justified by the fact that the final-year medical students in Syria have relatively good encounter with patients.[11]

The results of our study also showed that the final-year medical students had better clinical judgment than the fourth-year students (mean 2.69 points [1.12] vs 2.47 points [1.15]; adjusted $P=0.01$ ). This is comparable to a study conducted by Boshuizen et al. on 223 students, showing that students with good clinical reasoning are those who had passed more tests at medical school and had achieved more progress in academic years.[24]

On the other hand, having previous clinical experience did not have significant correlation with clinical judgment. This was in contrast to a previous study which demonstrated that clinical experience correlated with increased clinical knowledge.[25] It was also in contrast to a study conducted by Humbert et al. on 314 fourth-year medical students; 40 Emergency Medicine residents, and 13 expert emergency physicians, which showed improvement in clinical test performance with more clinical experience.[26] This difference between our results and the results of the previous study could be due to the lack of considerable differences in clinical experiences between these three clinical years, as applied in Syrian Universities.[27]

Our results showed that $72.4 \%$ of the final-year participants had an overall score of 7 points or more in the overall score (mean 6.39 points [SD 1.57]). This finding was similar to another study conducted by Fürstenberg et al. on 67 advanced undergraduate medical students, which showed that the average clinical reasoning scores was $2.78( \pm 0.58$, maximum score of 5$)$ and the medical knowledge was $73.3( \pm$ 9.1, maximum score of 100).[28]

Interestingly, our study showed that females achieved better clinical judgment scores than their male peers (P-value $<0.001)$. A previous study that included 290 medical students showed that females scored significantly higher in clinical reasoning problems (CRPs) than males. The researchers explained this result by the women's tendency to be more thorough and deliberate when considering clinical problems. [29] 
Our results showed that students who had fears of being infected expressed the need of supervision. This need was also demonstrated during the Influenza pandemic in the UK when HCWs expressed the need for the support and supervision of their managers.[30]

The present study showed that the better knowledge scores the students had, the more likely they would be afraid of getting infected. This also goes in accordance with a previous Serbian study conducted by Smolovic et al. on 69 university students, which showed that the more knowledge the students had about Tuberculosis, the more they had fears of the infection.[31]

The willingness to participate in the medical efforts against COVID-19 was significantly lower in students who had fears of the infection. This result, again, may complete some conclusions drawn from previous studies that have been held during other pandemics. For example, a Singaporean study that assessed the risk perception among more than $15,000 \mathrm{HCWs}$ of first-responders during the SARS epidemic in 2003, showed that $76 \%$ of the respondents were afraid of the infection, but $69.5 \%$ of them accepted the risk as a part of their job.[32] However, another study from Germany revealed that $28 \%$ of participating HCWs may give up work to protect themselves and their families.[30]

Regarding preventive measures, our results showed that although $1036(86.4 \%)$ of the final-year students answered, subjectively, that they know how to follow the prevention rules, only 707 (58.9\%) of them answered prevention-related questions correctly. This is comparable to a study conducted by Modi et al. on 1562 medical students and staff members in Mumbai which showed that $71.2 \%$ of respondents correctly answered questions related to COVID-19 awareness, knowledge, and infection control.[33]

Having advanced English level was associated with answering general medical knowledge questions correctly and it has a profound effect on clinical judgment score and overall score. This may reflect the relationship between English proficiency and the ability to gain more access generally to reliable medical information, and particularly to those related to COVID-19. These findings are comparable to those of some other studies that demonstrated the importance of English proficiency in medical education.[34, 35] An important aspect of this study is the large number (1199 final-year students) of participants. This number may represent approximately one-third of all the final-year medical students nation-wide, which allowed us to make adequate analysis that led to the results that may be considered as representative. [36] Moreover, this study was designed to assess various aspects of general knowledge and clinical judgment in the most possibly comprehensive way and the survey was distributed in conjunction with the very first documented cases of COVID-19 in Syria. This, in our opinion, helped to minimize the potential bias that may result from stress.

However, our study has several limitations. Firstly, only students from Syrian Universities were included, that being said, we think that further studies from other countries may confirm our conclusions. Secondly, the survey wasn't time-limited. This aspect was treated carefully because of the mediocre quality of internet connection in some areas. 
On the other hand, this survey was conducted online. We do believe that in the light of the lockdown procedures, and in accordance with the WHO recommendations about social distancing,[2] this study is an adequate proof that online surveys may serve as a practical, low-cost, and reliable mean to conduct such studies.

In fact, more efforts are to be made in order to integrate advanced technologies in medicine and biomedical research fields, while trying at the same time to enhance the trust and security of such techniques.[22, 37]

\section{Conclusions}

This study demonstrated that the final-year medical students may represent a potential solution, under adequate and suitable supervision, to support fragile health systems especially in a war-torn area during pandemic scenarios. Lessons of these scenarios might also include the need of integrating a special "Crisis Response" training to the medical education curriculum worldwide. Moreover, future in-depth research might also help to define the most appropriate roles of these students in the times of crisis and pandemics. Finally, all efforts must be made in order to ameliorate the self-protection practices of junior HCWs and volunteers.

\section{Abbreviations}

SARS-CoV-2: Severe Acute Respiratory Syndrome Coronavirus 2.

WHO: World Health Organization.

SARS: Severe Acute Respiratory Syndrome.

MERS: Middle East Respiratory Syndrome

HCWs: Healthcare Workers

AAMC: Association of American Medical Colleges

UK: United Kingdom.

ANOVA: Analysis of Variance

CRPs: Clinical Reasoning Problems

\section{Declarations}

\section{Ethics approval and consent to participate:}


The study was approved by the Scientific Ethical Committee of the Faculty of Medicine, Damascus University, and was conducted in line with the Declaration of Helsinki. Written informed consent was obtained from each respondent on the first electronic page of the questionnaire. Participants' privacy was guaranteed throughout the study. All participants had the right to withdraw at any stage of the study. Moreover, all incomplete responses were considered as withdrawal and were excluded from the analysis. All participants were 18-year-old or older.

\section{Consent for publication:}

Not Applicable.

\section{Availability of data and materials:}

All data generated or analyzed during this study are available from the corresponding author on reasonable request

\section{Authors' contributions:}

TA designed the study. TA, RAKa, MH and MAlm established the questionnaire. LA, RAKa, MH, and MAlm searched the literature. TA, LA, RAKa, MH, MAlm and MAlh collected the data. TA and RAKh analyzed the data. TA, LA, and RAKh interpreted the data. TA, LA, RAKa, MH, MAlm and RAKh wrote the first draft. TA, LA, RAKh and MAlh contributed to the final draft. All authors approved the final manuscript.

\section{Competing interests:}

The authors declare no conflict of interest.

\section{Funding:}

The authors received no specific funding for this work.

\section{Acknowledgement:}

The authors thank Angie Mouki and Joseph Sneij for the proofreading of this manuscript.

\section{References}


1. Bhagavathula AS, Aldhaleei WA, Rahmani J, Mahabadi MA, Bandari DK. Knowledge and Perceptions of COVID-19 Among Health Care Workers: Cross-Sectional Study. JMIR Public Health Surveill. 2020;6:e19160-e19160.

2. WHO. covid-strategy-update-14april2020.pdf. 2020. https://www.who.int/docs/defaultsource/coronaviruse/covid-strategy-update-14april2020.pdf. Accessed 4 Jun 2020.

3. WHO | Ebola health worker infections. WHO. http://www.who.int/features/ebola/health-careworker/en/. Accessed 17 May 2020.

4. Nuzzo JB, Meyer D, Snyder M, Ravi SJ, Lapascu A, Souleles J, et al. What makes health systems resilient against infectious disease outbreaks and natural hazards? Results from a scoping review. BMC Public Health. 2019;19:1-9.

5. Chowell G, Abdirizak F, Lee S, Lee J, Jung E, Nishiura H, et al. Transmission characteristics of MERS and SARS in the healthcare setting: a comparative study. BMC Med. 2015;13. doi:10.1186/s12916015-0450-0.

6. Paterlini M. On the front lines of coronavirus: the Italian response to covid-19. BMJ. 2020;368. doi:10.1136/bmj.m1065.

7. Miller DG, Pierson L, Doernberg S. The Role of Medical Students During the COVID-19 Pandemic. Ann Intern Med. 2020. doi:10.7326/M20-1281.

8. AAMC. meded-April-14-Guidance-on-Medical-Students-Participation-in-Direct-Patient-ContactActivities.pdf. 2020. https://www.aamc.org/system/files/2020-04/meded-April-14-Guidance-onMedical-Students-Participation-in-Direct-Patient-Contact-Activities.pdf. Accessed 2 Jun 2020.

9. Harvey A. Covid-19: medical schools given powers to graduate final year students early to help NHS. BMJ. 2020;368. doi:10.1136/bmj.m1227.

10. WHO EMRO | Syrian Arab Republic | Countries. http://www.emro.who.int/countries/syr/index.html. Accessed 17 May 2020.

11. Sawaf B, Abbas F, Idris A, Al Saadi T, Ibrahim N. Specialty preference and intentions to study abroad of Syrian medical students during the crisis. BMC Med Educ. 2018;18:39-39.

12. Delice A. The sampling issues in quantitative research. Educational Sciences: Theory and Practice. 2010;10:2001-18.

13. World Health Organization. Clinical management of severe acute respiratory infection (SARI) when COVID-19 disease is suspected: interim guidance, 13 March 2020. Geneva: World Health Organization; 2020. https://apps.who.int/iris/handle/10665/331446.

14. R Core Team (2018). R: A language and environment for statistical computing. R Foundation for Statistical Computing, Vienna, Austria. URL https://www.R-project.org/.

15. Michael Waskom, Olga Botvinnik, Joel Ostblom, Maoz Gelbart, Saulius Lukauskas, Paul Hobson, et al. mwaskom/seaborn: v0.10.1 (April 2020). Zenodo; 2020. doi:10.5281/zenodo.3767070.

16. Starr I. Influenza in 1918: Recollections of the Epidemic in Philadelphia. Ann Intern Med. 2006;145:138-40. 
17. Elrggal ME, Karami NA, Rafea B, Alahmadi L, Al Shehri A, Alamoudi R, et al. Evaluation of preparedness of healthcare student volunteers against Middle East respiratory syndrome coronavirus (MERS-CoV) in Makkah, Saudi Arabia: a cross-sectional study. J Public Health. 2018;26:607-12.

18. Bukhsh A, Hussain S, Rehman IU, Mallhi TH, Khan YH, Khaliel AM, et al. Awareness and perception of seasonal influenza (Flu) among health science and Non-Health science university students in Pakistan: A nationwide survey. Pak J Pharm Sci. 2019;32 4(Supplementary):1789-96.

19. Kamimura A, Trinh HN, Weaver S, Chernenko A, Nourian MM, Assasnik N, et al. Knowledge and Perceptions of Influenza Vaccinations Among College Students in Vietnam and the United States. J Prev Med Public Health Yebang Uihakhoe Chi. 2017;50:268-73.

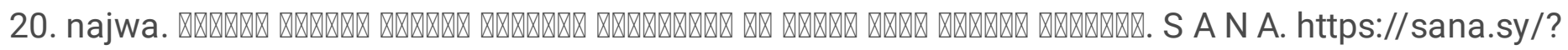
$p=1123438$. Accessed 17 May 2020.

21. Taghrir MH, Borazjani R, Shiraly R. COVID-19 and Iranian Medical Students; A Survey on Their Related-Knowledge, Preventive Behaviors and Risk Perception. Arch Iran Med. 2020;23:249-54.

22. Alsuliman T, Humaidan D, Sliman L. Machine learning and artificial intelligence in the service of medicine: Necessity or potentiality? Curr Res Transl Med. 2020. doi:10.1016/j.retram.2020.01.002.

23. McGowan BS, Wasko M, Vartabedian BS, Miller RS, Freiherr DD, Abdolrasulnia M. Understanding the factors that influence the adoption and meaningful use of social media by physicians to share medical information. J Med Internet Res. 2012;14:e117-e117.

24. Fürstenberg S, Oubaid V, Berberat PO, Kadmon M, Harendza S. Medical knowledge and teamwork predict the quality of case summary statements as an indicator of clinical reasoning in undergraduate medical students. GMS J Med Educ. 2019;36:Doc83.

25. Gao X, Wu Y, Zhang Y, Zhang N, Tang J, Qiu J, et al. Effectiveness of School-based Education on HIV/AIDS Knowledge, Attitude, and Behavior among Secondary School Students in Wuhan, China. PLOS ONE. 2012;7:e44881.

26. Humbert AJ, Besinger B, Miech EJ. Assessing clinical reasoning skills in scenarios of uncertainty: convergent validity for a Script Concordance Test in an emergency medicine clerkship and residency. Acad Emerg Med Off J Soc Acad Emerg Med. 2011;18:627-34.

27. Wan MSH, Tor E, Hudson JN. Construct validity of script concordance testing: progression of scores from novices to experienced clinicians. Int J Med Educ. 2019;10:174-9.

28. Fürstenberg S, Oubaid V, Berberat PO, Kadmon M, Harendza S. Medical knowledge and teamwork predict the quality of case summary statements as an indicator of clinical reasoning in undergraduate medical students. GMS J Med Educ. 2019;36:Doc83-Doc83.

29. Groves M, O'rourke P, Alexander $H$. The association between student characteristics and the development of clinical reasoning in a graduate-entry, PBL medical programme. Med Teach. 2003;25:626-31.

30. Ives J, Greenfield S, Parry JM, Draper H, Gratus C, Petts JI, et al. Healthcare workers' attitudes to working during pandemic influenza: a qualitative study. BMC Public Health. 2009;9:56. 
31. Koay TK. Knowledge and attitudes towards tuberculosis among the people living in Kudat District, Sabah. Med J Malaysia. 2004;59:502-11.

32. Mackler N, Wilkerson W, Cinti S. Will first-responders show up for work during a pandemic? Lessons from a smallpox vaccination survey of paramedics. Disaster Manag Response DMR Off Publ Emerg Nurses Assoc. 2007;5:45-8.

33. Modi PD, Nair G, Uppe A, Modi J, Tuppekar B, Gharpure AS, et al. COVID-19 Awareness Among Healthcare Students and Professionals in Mumbai Metropolitan Region: A Questionnaire-Based Survey. Cureus. 2020. doi:10.7759/cureus.7514.

34. Al-Qahtani M. Relationship between English Language, Learning Strategies, Attitudes, Motivation, and Students' Academic Achievement. Educ Med J. 2013;5.

35. Alsuliman T, Alasadi L, Mouki A, Alsaid B. Language of written medical educational materials for non-English speaking populations: an evaluation of a simplified bi-lingual approach. BMC Med Educ. 2019;19:418.

36. http://mohe.gov.sy/mohe/index.php?node=555\&cat=2863\&.

37. Almakhour M, Sliman L, Samhat AE, Gaaloul W. Trustless Blockchain-based Access Control in Dynamic Collaboration. 2018.

\section{Figures}

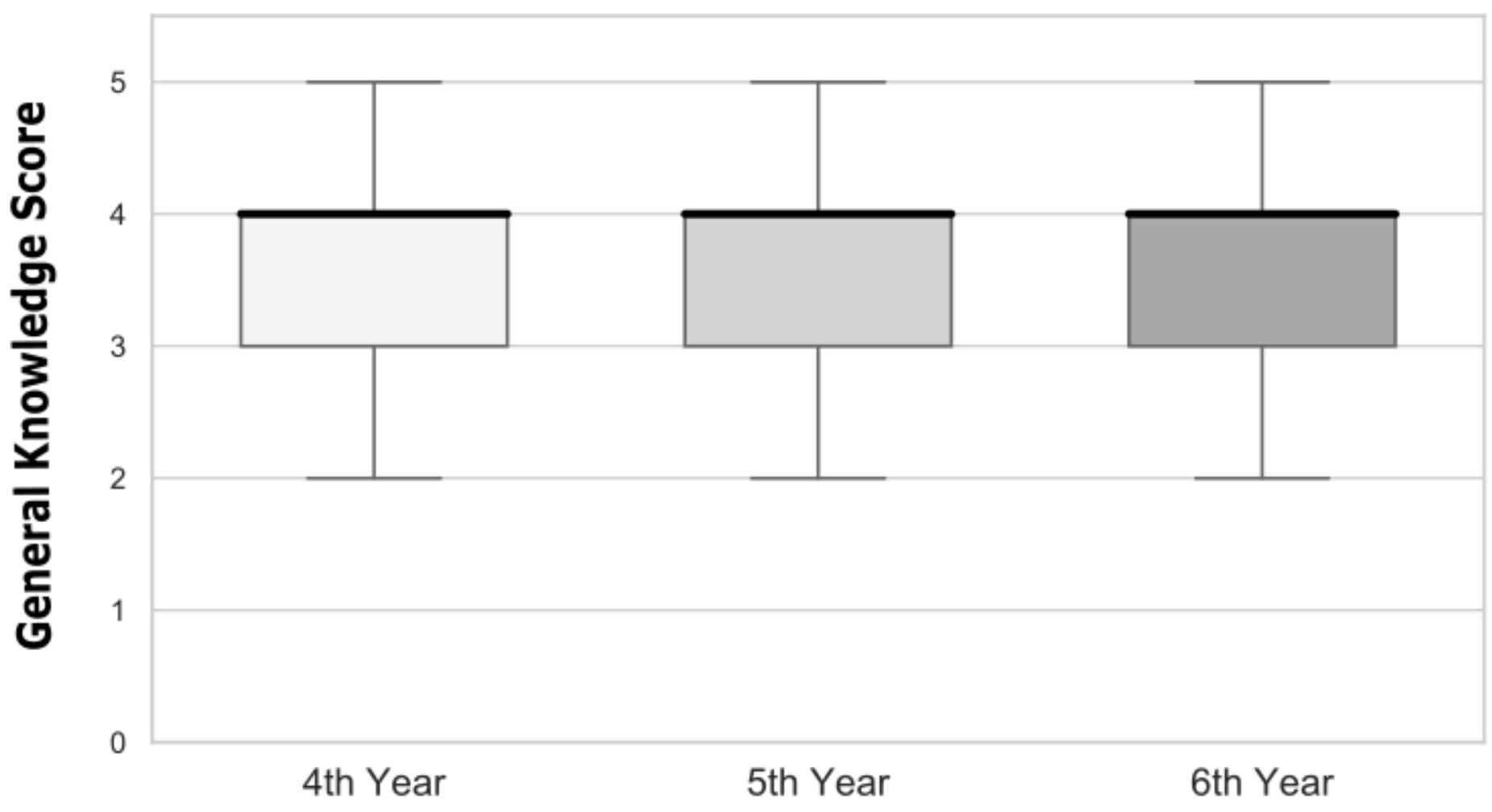

\section{Year of Study}


Figure 1

Comparison between results of the General knowledge Score among the fourth-, fifth-, and sixth-year participants. Comparison between the results of the General knowledge Score ( $\max =5$ points) among the fourth-, fifth-, and sixth-year medical students. There was no significant correlation between the year of the study and the obtained General knowledge Score.

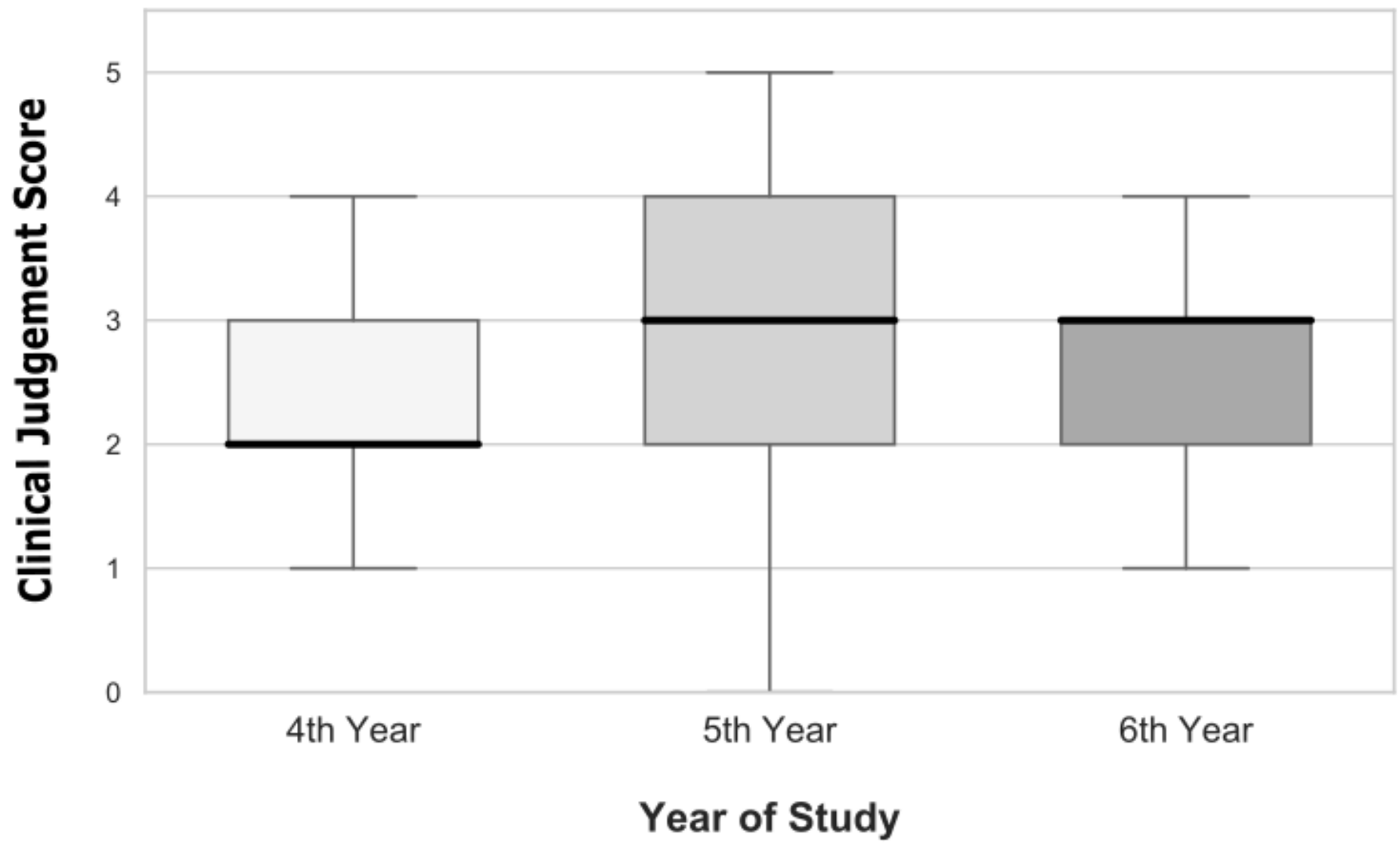

Figure 2

Comparison between results of the Clinical Judgment Score among the fourth-, fifth-, and sixth-year participants. Comparison between the results of the Clinical Judgment Score (max $=5$ points) among the fourth-, fifth-, and sixth-year medical students. Sixth-year students significantly scored higher than the fourth-year, but not the fifth-year, students. 


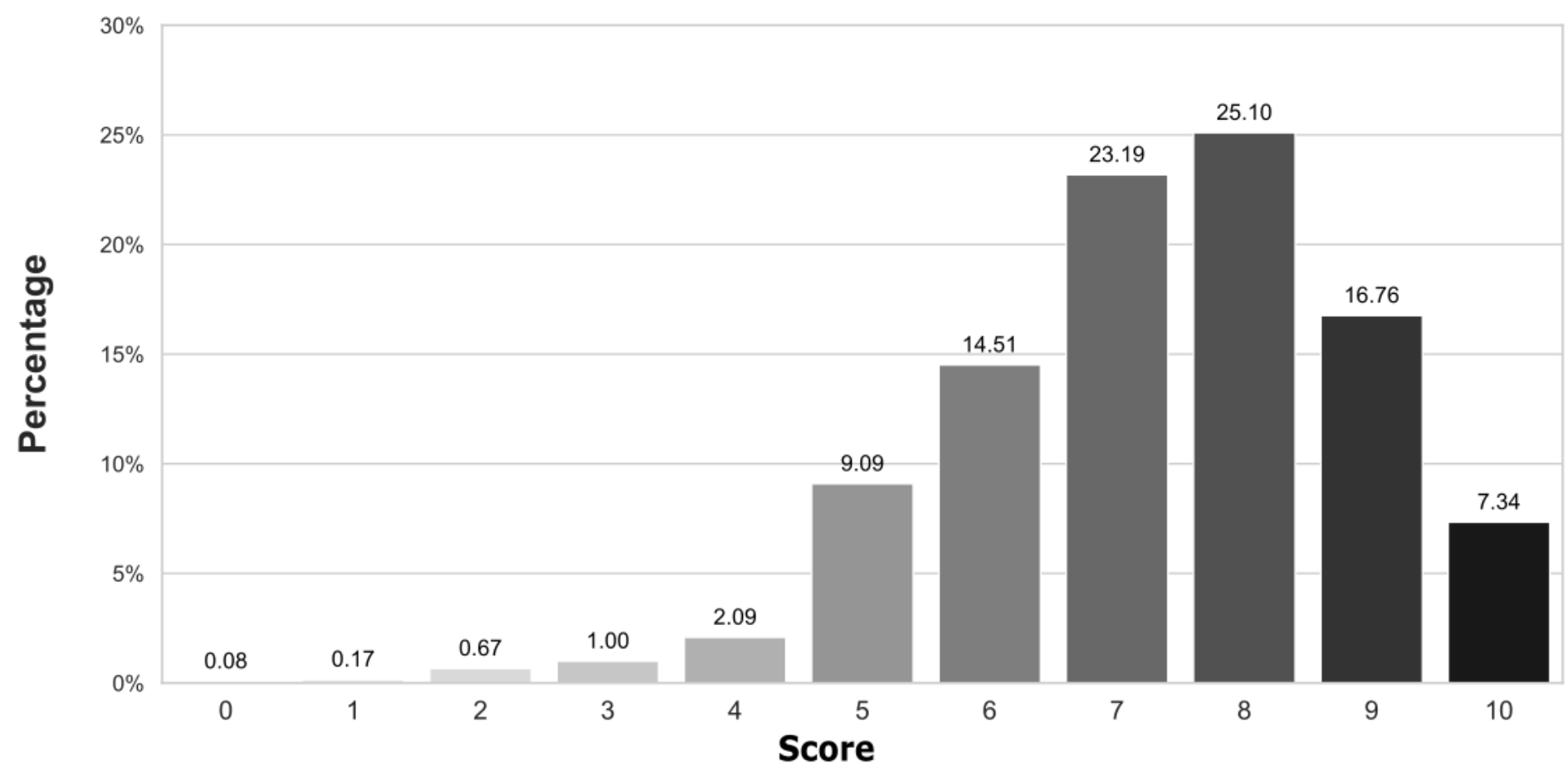

Figure 3

Results of the Overall Score ( $\max =10$ points) for the sixth-year medical students.

\section{Supplementary Files}

This is a list of supplementary files associated with this preprint. Click to download.

- Additionalfile1.docx 